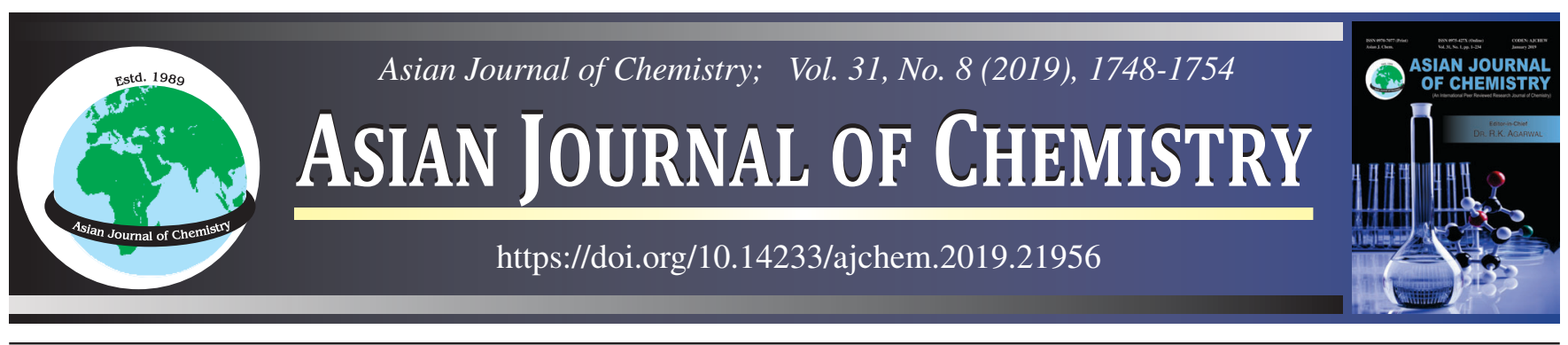

\title{
in silico Evaluation of 4-Amino-5-substituted-4H-1,2,4-triazole-3-thiol Derivatives against DNA Gyrase, COX-2 and Cathepsin B
}

\section{Anitha Kumari*, Shaheen Begum and K. Bharathi}

Institute of Pharmaceutical Technology, Sri Padmavati Mahila Visvavidyalayam, Tirupathi-517502, India

*Corresponding author: Fax: +91 877 2284531; E-mail: anithamedchem@gmail.com

Received: 24 January 2019; Accepted: 19 March 2019;

Published online: 28 June 2019;

AJC-19446

\begin{abstract}
Biological activities of 1,2,4-triazoles, in particular, anticancer, anti-inflammatory and antimicrobial activities are potentiated by the presence of thiol group and free amino groups. Enticed by this, a series of 1,2,4-triazole derivatives were designed by introducing different substituent groups at $5^{\text {th }}$ position of 4-amino- $4 \mathrm{H}-1,2,4$-triazole-3-thiol ring and their binding affinities were determined by molecular docking studies with the targets associated with bacterial infections, inflammation and cancer (DNA gyrase, cyclooxygenaseII (COX-2) and cathepsin B; PBD IDs: 1KZN, 3LN1 and 1SP4). Results revealed that all the compounds displayed good binding affinity towards the selected targets. The designed compounds showed relatively good affinity for cathepsin B and DNA gyrase enzymes when compared to COX-2. In comparison to aromatic groups, substitution with long aliphatic chains at $5^{\text {th }}$ position significantly improved the binding properties of the compounds towards the targets. 1,2,4-Triazole ring was found to be crucial to form hydrogen bonding interactions with the active site amino acid residues. Stearyl and oleayl substituted derivatives $\left(\mathrm{B}_{6}\right.$ and $\left.\mathrm{B}_{7}\right)$ exhibited superior binding properties and thus disclosing their pharmacological significance. Interestingly none of the compound showed affinity for permeability glycoprotein (P-gp), suggesting that their cellular uptake will be good in cancer cells.
\end{abstract}

Keywords: 1,2,4-Triazoles, Molecular docking, Cathepsin B, Cyclooxygenase-II, DNA gyrase subunit B.

ᄂ _ - - - - - - - - - - - - - - - - - - - - - - - - - - - - -

\section{INTRODUCTION}

1,2,4-Triazole (pyrrodiazole) is a basic heterocyclic nucleus possessing broad range of biological activities. Good number of anti-inflammatory, analgesic, antifungal, anticonvulsant, antiviral, anticancer, antimicrobial, antimalarial, antidepressant, cardioprotective and antianxiety agents contain 1,2,4-triazole ring as pharmacophoric unit in their structure [1-3]. Being an important pharmacophore that can be used to produce novel functional drug candidates, triazole moiety also provides a very flexible and effective pathway to construct a wide variety of bioactive and therapeutically useful molecules. Broad spectrum of activity, low toxicity and attractive pharmacokinetic cum pharmacodynamic profiles made 1,2,4-triazoles as interesting and challenging candidates, attracted by medicinal chemists [4]. One of the interesting structural feature of 1,2,4-triazole ring is presence of three nitrogen atoms (electron rich), which can participate in a variety of bonded and non-bonded interactions with the active site of receptors viz., hydrogen bonds, ion-dipole bonds and van der Waals interactions [5].
1,2,4-Triazole bearing compounds demonstrate potent anticancer activity by acting on various targets associated with tumor growth such as epithelial growth factor receptor, tumor necrosis factor $\mathrm{TNF} \alpha$, integrin avb3 receptor, cathepsin B etc. Anastrozole and letrozole are 1,2,4-triazole based drugs that are clinically recommended for the treatment of breast cancer, which act by aromatase inhibition [6,7]. 4-Amino 1,2,4-triazoles competitively inhibit cathepsin $\mathrm{B}$ and cathepsin $\mathrm{H}$ and their potency is altered based on nature and position of substituent groups on 1,2,4-triazole ring [8]. N-Bridged heterocyclic derivatives of 1,2,4-triazoles like 1,2,4-triazolo[3,4-b]thiadiazole and 1,3,4-oxadiazoles also possess good anticancer activities [9].

Good anti-inflammatory and analgesic activities have been reported for 3,5-substituted 1,2,4-triazoles. Bis-triazoles, benzoxazolinone-substituted triazoles and various substituted triazoles display cyclooxygenase-II inhibitory activity [6,10]. 1,2,4Triazoles bearing a free thiol group at $5^{\text {th }}$ position and 3,4dimethoxy phenyl ring at $3^{\text {rd }}$ position exerted anti-inflammatory activity with lower acute toxicity which is a common side effect

This is an open access journal, and articles are distributed under the terms of the Attribution 4.0 International (CC BY 4.0) License. This license lets others distribute, remix, tweak, and build upon your work, even commercially, as long as they credit the author for the original creation. You must give appropriate credit, provide a link to the license, and indicate if changes were made. 
of NSAIDs [11]. It has been also reported that 1,2,4-triazole derivatives possessing free thiol group at $5^{\text {th }}$ position disclosed antibacterial, anti-inflammatory and antitubercular activities [12]. The presence of free amino group at $4^{\text {th }}$ position of $1,2,4-$ triazole nucleus may also impart greater inhibitory effect against one or more types of bacteria [13].

Presence of SH group in triazole moiety seems to improve the biological activities and antioxidant activity [14]. Thiol group (sulfhydryl group) acts as free radical scavenger and potent antioxidant agent, for example several natural thiols such as glutathione, $\mathrm{N}$-acetylcysteine and homocysteine are potent antioxidant agents and also exhibit various important biological activities due to the presence of thiol group in their structures [15].

The survey of literature suggested that 1,2,4-triazole can function as an important scaffold by virtue of its hydrogen bonding ability. In this study, it was planned to design various 1,2,4-triazole derivatives by introducing different substituent groups at $5^{\text {th }}$ position of 4-amino- $4 H-1,2,4$-triazole-3-thiol ring. The basic skeleton namely, 4-amino- $4 H$-1,2,4-triazole-3-thiol ring includes a free thiol and a free amino group which may impart a notable effect in hydrogen bond formation with target binding site. To explore their binding efficacy towards the targets such as DNA gyrase, COX-2 and cathepsin B, associated with antibacterial, anti-inflammatory and anticancer activities, molecular docking was performed.

\section{EXPERIMENTAL}

in silico Analysis of drug likeness and pharmacokinetic properties: Drug likeness explains an integrated equilibrium between molecular properties and structural features that evaluate whether a compound is comparable to already existing drugs. Lipinski rule of five is commonly used to evaluate drug likeness properties of a compound. Molinspiration on-line property calculation tool is applied to determine Lipinski's molecular properties, number of rotatable bonds, together with topological polar surface area (TPSA) and molecular volume (a determinant of transport characteristics) and some other molecular descriptors (by http://www.molinspiration.com/cgibin/properties) [16-20].

Important pharmacokinetic properties such as gastro intestinal absorption, brain permeability etc. were calculated by using Swiss ADME web service (http://www.swissadme.ch/). Probable targets for the title compounds were predicted by Swiss target prediction analysis, using http://www.swiss target prediction.ch, a web server, based on the two and three dimensional measures matching with known ligands [21-23].

Molecular docking studies: Molecular docking studies were performed on a series of 3-amino-5-substituted-4H-1,2,4triazole-3-thiol derivatives to predict their binding modes and interactions with target proteins, associated with the pharmacological potentiality of title compounds. Target proteins were obtained from the Protein Data Bank (PBD ID: 1KZN, DNA gyrase; PBD ID: 3LN1, COX-2; PBD ID: 1SP4, cathepsin B). Chemical structures of the title compounds were drawn using Chem and Bio Draw 12.0, a flexible tool and are saved as mol2 files using Chem and Bio 3D version12.0.

Molecular docking programme is an essential computational technique, useful to identify the best possible conformation of the ligand in a target protein that plays a major role in drug design. Swiss Dock, a computational programme was developed for carrying out molecular docking, fragment based drug design and lead optimization [24,25].

\section{RESULTS AND DISCUSSION}

in silico Analysis of drug likeness and pharmacokinetic properties: The title compounds complied with Lipinski's rule of five, indicating good oral bioavailability (Table-1) and showed good bioactivity scores for kinase inhibitor $(-0.28$ to -1.22$)$ and as enzyme inhibitors (-0.33 to -1.03$)$. Swiss ADME results indicated good oral bioavailability and gastrointestinal absorption for all compounds except for $\mathrm{B}_{8}, \mathrm{~B}_{13}$ and $\mathrm{B}_{17}$ which showed low gastrointestinal absorption. 3,5-Dinitro substituted derivative $\left(\mathrm{B}_{17}\right)$ was resulted as a P-glycoprotein (Permeability glycoprotein) substrate and displayed relatively low GI absorption as per Swiss ADME that possesses drug likeness property [26].

TABLE-1

ANALYSIS OF DRUG LIKENESS AND BIOACTIVITY SCORES

\begin{tabular}{|c|c|c|c|c|c|c|}
\hline Compound & $\mathrm{R}_{1}$ & Lipinski rule & GPCR ligand & Kinase inhibitor & Protease inhibitor & Enzyme inhibitor \\
\hline $\mathrm{B}_{1}$ & $\mathrm{C}_{6} \mathrm{H}_{5}$ & YES & -1.97 & -1.22 & -2.15 & -1.03 \\
\hline $\mathbf{B}_{2}$ & 4- $\mathrm{ClC}_{6} \mathrm{H}_{4}$ & YES & -1.77 & -1.09 & -2.02 & -0.97 \\
\hline $\mathbf{B}_{3}$ & $\mathrm{C}_{6} \mathrm{H}_{5}-\mathrm{CH}=\mathrm{CH}$ & YES & -1.27 & -0.67 & -1.59 & -0.80 \\
\hline $\mathbf{B}_{4}$ & 2-Pyridyl & YES & -1.89 & -0.98 & -2.12 & -0.93 \\
\hline $\mathbf{B}_{5}$ & 2-OH, $5-\mathrm{NH}_{2}-\mathrm{C}_{6} \mathrm{H}_{3}$ & YES & -1.71 & -1.02 & -1.92 & -0.91 \\
\hline $\mathbf{B}_{6}$ & $\mathrm{C}_{18} \mathrm{H}_{36} \mathrm{O}_{2}$ (stearyl) & YES & -0.48 & -0.28 & -0.54 & -0.39 \\
\hline $\mathbf{B}_{7}$ & $\mathrm{C}_{18} \mathrm{H}_{34} \mathrm{O}_{2}$ (oleayl) & YES & -0.43 & -0.30 & -0.54 & -0.33 \\
\hline $\mathbf{B}_{8}$ & 2-OH, 3,5-( $\left(\mathrm{NO}_{2}\right)_{2} \mathrm{C}_{6} \mathrm{H}_{3}$ & YES & -1.19 & -0.57 & -1.27 & -0.52 \\
\hline $\mathbf{B}_{9}$ & $2-\mathrm{OH} \mathrm{C}{ }_{6} \mathrm{H}_{5}$ & YES & -1.76 & -1.07 & -1.96 & -0.85 \\
\hline $\mathbf{B}_{10}$ & $2,4-(\mathrm{Cl})_{2} \mathrm{C}_{6} \mathrm{H}_{4}$ & YES & -1.52 & -0.93 & -1.81 & -0.89 \\
\hline $\mathbf{B}_{11}$ & $4-\mathrm{NO}_{2} \mathrm{C}_{6} \mathrm{H}_{5}$ & YES & -1.67 & -1.02 & -1.81 & -0.89 \\
\hline $\mathbf{B}_{12}$ & $4-\mathrm{CH}_{3} \mathrm{C}_{6} \mathrm{H}_{5}$ & YES & -1.84 & -1.15 & -2.05 & -1.02 \\
\hline $\mathbf{B}_{13}$ & $4-\mathrm{Cl}, 3-\mathrm{NO}_{2}-\mathrm{C}_{6} \mathrm{H}_{3}$ & YES & -1.50 & -0.88 & -1.79 & -0.84 \\
\hline $\mathbf{B}_{14}$ & $3,5-\left(\mathrm{OCH}_{3}\right)_{2} \mathrm{C}_{6} \mathrm{H}_{3}$ & YES & -1.37 & -0.68 & -1.57 & -0.69 \\
\hline $\mathbf{B}_{15}$ & $2-\mathrm{Cl} \mathrm{C}_{6} \mathrm{H}_{5}$ & YES & -1.77 & -1.09 & -2.05 & -0.95 \\
\hline $\mathbf{B}_{16}$ & 4- $\mathrm{NH}_{2} \mathrm{C}_{6} \mathrm{H}_{5}$ & YES & -1.72 & -0.92 & -1.86 & -0.80 \\
\hline $\mathbf{B}_{17}$ & $3,5-\left(\mathrm{NO}_{2}\right)_{2} \mathrm{C}_{6} \mathrm{H}_{4}$ & YES & -1.26 & -0.67 & -1.37 & -0.66 \\
\hline $\mathbf{B}_{18}$ & 4- $\mathrm{OCH}_{3} \mathrm{C}_{6} \mathrm{H}_{5}$ & YES & -1.66 & -0.99 & -1.85 & -0.88 \\
\hline
\end{tabular}


No single compound of the series displayed BBB penetration, showing that they are devoid of CNS side effects. Predicted pharmacokinetic properties (ADME) of title compounds suggested that they can act as orally active and potential drug candidates with a predicted high safety profile (Table-2). P-Glycoprotein is an ATP-binding cassette transporter that selectively pumps out drug molecules into gastrointestinal tract and reduces their therapeutic efficacy. It is highly expressed in cancer cells and if a drug molecule is a P-glycoprotein substrate then it will be expelled out of the cell, its absorption and bioavailability are significantly reduced. P-glycoprotein has potential role in cellular uptake of drugs and seriously limits drug effectiveness and in case of cancer, it is a major hurdle leading to multi resistant phenomenon. Theoretically it can be assumed that P-glycoprotein substrates are ineffective in cancer treatment $[27,28]$. The designed compounds do not have affinity for P-glycoprotein, so it can be predicted that cellular uptake will not be an issue for the compounds in the cancer cells.

Molecular docking studies: The designed compounds were docked within the crystal structure of targets and were tested for the binding energies and hydrogen bonding interactions with active site. Docking studies provide the information to find out the crucial residues at the active site of target. Ranking or grading of the compounds is based mainly on the binding modes with high binding energies and better number of hydrogen bonds. Output of all compounds was shown in energy terms in $\mathrm{kcal} / \mathrm{mol}$ as shown in Table-3 and their interactions were predicted in Table- 4 .

TABLE-2

SWISS ADME AND SWISS TARGET PREDICTION DATA FOR TITLE COMPOUNDS

\begin{tabular}{|c|c|c|c|c|c|}
\hline Compound & Oral bioavailability & $\mathrm{BBB}$ penetration & P-gp substrate & $\begin{array}{l}\text { Drug likeness and } \\
\text { bioavailability score }\end{array}$ & Target class \\
\hline $\mathbf{B}_{1}$ & High & No & No & Yes $(0.55)$ & Enzyme \\
\hline $\mathbf{B}_{2}$ & High & No & No & Yes $(0.55)$ & Membrane receptor \\
\hline $\mathbf{B}_{3}$ & High & No & No & Yes $(0.55)$ & Enzyme \\
\hline $\mathbf{B}_{4}$ & High & No & No & Yes $(0.55)$ & Membrane receptor \\
\hline $\mathbf{B}_{5}$ & High & No & No & Yes $(0.55)$ & Enzyme \\
\hline $\mathbf{B}_{6}$ & High & No & No & Yes $(0.55)$ & Enzyme \\
\hline $\mathbf{B}_{7}$ & High & No & No & Yes $(0.55)$ & Enzyme \\
\hline $\mathbf{B}_{8}$ & Low & Low & No & Yes $(0.55)$ & Enzyme \\
\hline $\mathbf{B}_{9}$ & High & No & No & Yes $(0.55)$ & Enzyme \\
\hline $\mathbf{B}_{10}$ & High & No & No & Yes $(0.55)$ & Enzyme \\
\hline$B_{11}$ & High & No & No & Yes $(0.55)$ & Enzyme \\
\hline$B_{12}$ & High & No & No & Yes $(0.55)$ & Enzyme \\
\hline $\mathbf{B}_{13}$ & Low & Low & No & Yes $(0.55)$ & Enzyme \\
\hline $\mathbf{B}_{14}$ & High & No & No & Yes $(0.55)$ & Enzyme \\
\hline $\mathbf{B}_{15}$ & High & No & No & Yes $(0.55)$ & Enzyme \\
\hline $\mathbf{B}_{16}$ & High & No & No & Yes $(0.55)$ & Kinase \\
\hline $\mathbf{B}_{17}$ & low & Low & yes & Yes $(0.55)$ & Enzyme \\
\hline $\mathbf{B}_{18}$ & High & No & No & Yes $(0.55)$ & Enzyme \\
\hline
\end{tabular}

TABLE-3

DOCKING SCORES OF TITLE COMPOUNDS OBTAINED FROM SWISS DOCK STUDIES

\begin{tabular}{|c|c|c|c|c|c|c|}
\hline \multirow{2}{*}{ Compound } & \multicolumn{2}{|c|}{ DNA gyrase subunit B } & \multicolumn{2}{|c|}{ COX-2 } & \multicolumn{2}{|c|}{ Cathepsin B } \\
\hline & $\Delta \mathrm{G}(\mathrm{Kcal} / \mathrm{mol})$ & Full fitness & $\Delta \mathrm{G}(\mathrm{Kcal} / \mathrm{mol})$ & Full fitness & $\Delta \mathrm{G}(\mathrm{Kcal} / \mathrm{mol})$ & Full fitness \\
\hline $\mathbf{B}_{1}$ & -7.55 & -1311.81 & -7.55 & -2257.16 & -7.23 & -1184.77 \\
\hline $\mathbf{B}_{2}$ & -7.69 & -1312.84 & -7.59 & -2258.96 & -7.33 & -1186.57 \\
\hline $\mathbf{B}_{3}$ & -7.95 & -1311.72 & -8.11 & -2259.11 & -7.75 & -1175.70 \\
\hline $\mathbf{B}_{4}$ & -7.60 & -1312.65 & -7.45 & -2257.81 & -7.55 & -1190.81 \\
\hline $\mathbf{B}_{5}$ & -7.90 & -1307.75 & -7.61 & -2253.39 & -7.56 & -1183.44 \\
\hline $\mathbf{B}_{6}$ & -9.09 & -1368.66 & -8.83 & -2314.72 & -9.11 & -1240.77 \\
\hline $\mathbf{B}_{7}$ & -9.04 & -1362.11 & -8.88 & -2307.14 & -9.39 & -1236.81 \\
\hline $\mathbf{B}_{8}$ & -8.28 & -1281.27 & -8.75 & -2229.57 & -8.10 & -1162.13 \\
\hline $\mathbf{B}_{9}$ & -7.99 & -1311.72 & -7.55 & -2262.58 & -7.53 & -1188.10 \\
\hline $\mathbf{B}_{10}$ & -8.04 & -1315.91 & -7.74 & -2261.70 & -7.50 & -1192.64 \\
\hline $\mathbf{B}_{11}$ & -8.10 & -1295.34 & -7.87 & -2238.14 & -7.42 & -1167.00 \\
\hline $\mathbf{B}_{12}$ & -8.00 & -1315.15 & -7.68 & -2260.28 & -7.28 & -1185.71 \\
\hline $\mathbf{B}_{13}$ & -8.32 & -1308.78 & -8.12 & -2247.35 & -7.68 & -1180.50 \\
\hline $\mathbf{B}_{14}$ & -7.95 & -1297.65 & -8.21 & -2248.96 & -7.66 & -1173.70 \\
\hline $\mathbf{B}_{15}$ & -7.89 & -1316.76 & -7.84 & -2266.83 & -7.35 & -1190.63 \\
\hline$B_{16}$ & -7.99 & -1320.72 & -7.60 & -2260.27 & -7.29 & -1194.10 \\
\hline $\mathbf{B}_{17}$ & -8.30 & -1287.81 & -8.45 & -2229.78 & -7.92 & -1157.05 \\
\hline $\mathbf{B}_{18}$ & -8.02 & -1312.98 & -7.93 & -2259.97 & -7.39 & -1184.14 \\
\hline Clorobiocin & -10.08 & -1450.25 & - & - & - & - \\
\hline Celecoxib & - & - & -10.17 & -2275.86 & - & - \\
\hline NS-134 & - & - & - & - & -10.35 & -1164.35 \\
\hline
\end{tabular}




\begin{tabular}{|c|c|c|c|c|c|c|}
\hline \multirow{3}{*}{ Compound } & \multicolumn{5}{|c|}{$\begin{array}{l}\text { TABLE-4 } \\
\text { DEPICTION OF INTERACTING AMINO ACIDS AND CORRESPONDING } \\
\text { BOND LENGTHS BETWEEN THE LIGAND AND STUDIED TARGETS }\end{array}$} & \\
\hline & \multicolumn{2}{|c|}{ DNA gyrase subunit B } & \multicolumn{2}{|l|}{$\mathrm{COX}-2$} & \multicolumn{2}{|c|}{ Cathepsin B } \\
\hline & Interacting amino acids & Bond length & Interacting amino acids & Bond length & Interacting amino acids & Bond length \\
\hline $\mathbf{B}_{1}$ & LIG 1H6-ASP 73 OD1 & 1.879 & LIG 1H-GLU $222 \mathrm{O}$ & 2.498 & LIG 1H-CYS $100 \mathrm{O}$ & 2.602 \\
\hline $\mathbf{B}_{2}$ & LIG 1H1-ASP 73 OD1 & 1.866 & LIG 1H2-HEME 605 O & 2.054 & LIG 1 H1-GLU 122 O & 2.018 \\
\hline $\mathbf{B}_{3}$ & LIG 1H7-ASP-73-OD1 & 1.895 & LIG 1H6-HEME 605 O & 2.101 & LIG 1 H7-GLU 122 O & 2.100 \\
\hline $\mathbf{B}_{4}$ & LIG 1H2-ASP-73 OD1 & 1.858 & LIG 1H-GLU $222 \mathrm{O}$ & 2.176 & LIG 1 H2-CYS 252 O & 2.450 \\
\hline $\mathbf{B}_{5}$ & LIG 1H1-ASP-73-OD1 & 1.900 & LIG 1H-THR 198 O & 2.537 & LIG 1 H2-HSD $111 \mathrm{~N}$ & 2.239 \\
\hline \multirow[t]{5}{*}{$B_{6}$} & LIG 1H-GLY 117 O & 2.879 & LIG 1H1-GLY $221 \mathrm{O}$ & 2.140 & LIG 1 H2-GLU $122 \mathrm{O}$ & 1.977 \\
\hline & LIG 1H-GLU 42 O & 1.968 & LIG 1H2-ASP 215 O & 1.921 & LIG 1N1-TRP $221 \mathrm{H}$ & 2.378 \\
\hline & LIG 1H1-GLU $42 \mathrm{O}$ & 2.151 & & & LIG 1H2-GLU $122 \mathrm{O}$ & 2.336 \\
\hline & LIG 1H1-ASN 46 O & 2.541 & & & LIG 1H-HSE $110 \mathrm{~N}$ & 2.546 \\
\hline & LIG 1H-ASN 46 O & 2.314 & & & LIG 1H1-HSE $119 \mathrm{~N}$ & 1.189 \\
\hline \multirow[t]{4}{*}{$\mathbf{B}_{7}$} & LIG 1H1-GLU 42 OE1 & 2.252 & LIG 1H1-THR 198 O & 2.107 & LIG 1 H2-GLU 122 & 2.072 \\
\hline & LIG 1H1-GLN $72 \mathrm{O}$ & 2.403 & & & LIG $1 \mathrm{H} 2-\mathrm{GLU} 122 \mathrm{O}$ & 2.155 \\
\hline & LIG 1H-GLU 58 O & 2.742 & LIG 1H-HEME 605 O & 2.075 & LIG 1H-HSE $110 \mathrm{~N}$ & 2.132 \\
\hline & LIG $1 \mathrm{H} 2$-ASP $73 \mathrm{O}$ & 2.261 & LIG 1H1-HEME 605 O & 2.360 & LIG 1N1-TRP $221 \mathrm{H}$ & 2.293 \\
\hline $\mathbf{B}_{8}$ & LIG 1 O3-ASP-49 O & 3.409 & LIG 1N1-GLN 275 H & & LIG 1 H-HSE $110 \mathrm{~N}$ & 2.096 \\
\hline $\mathbf{B}_{9}$ & LIG 1H-ASP 73 OD1 & 2.093 & LIG1N1-GLN 275 H & 2.225 & LIG 1 H-GLY 198 O & 2.026 \\
\hline $\mathbf{B}_{10}$ & LIG 1H-ASP 73 OD1 & 2.177 & LIG 1H1-ASN 86 O & 1.963 & LIG 1H2-GLU $122 \mathrm{O}$ & 2.083 \\
\hline $\mathbf{B}_{11}$ & LIG 1H2-ASP 73 OD1 & 1.826 & LIG 1N1-PHE 566 H & 2.441 & LIG 1 O-GLY 198 H & 2.241 \\
\hline $\mathbf{B}_{12}$ & LIG 1H2-ASP 73 OD1 & 1.845 & LIG 1H-GLU $222 \mathrm{O}$ & 2.361 & LIG 1N-HSD $145 \mathrm{H}$ & 2.112 \\
\hline $\mathbf{B}_{13}$ & LIG 1H2-ASP 73 OD1 & 2.064 & LIG 1O1-GLN $189 \mathrm{H}$ & 1.951 & LIG 1 H2-GLU $122 \mathrm{O}$ & 2.141 \\
\hline $\mathbf{B}_{14}$ & LIG 1H1-ASP 73 OD1 & 1.885 & LIG 1O-GLN 275 H & 2.069 & LIG 1 O1-ARG $101 \mathrm{H}$ & 2.534 \\
\hline $\mathbf{B}_{15}$ & LIG 1H2-ASP $73 \mathrm{O}$ & 1.881 & LIG 1N1-GLN $275 \mathrm{H}$ & 2.402 & LIG 1 N1-TRP $221 \mathrm{H}$ & 2.327 \\
\hline$B_{16}$ & LIG 1H-ASP 73 OD1 & 2.076 & LIG 1H8-ARG 29 O & 2.386 & LIG 1 H7-GLY 198 O & 2.075 \\
\hline $\mathbf{B}_{17}$ & LIG 1H1-ASN 46 O & 2.517 & LIG 1O3-ALA $142 \mathrm{H}$ & 1.997 & LIG 1 H-HSE $110 \mathrm{~N}$ & 2.310 \\
\hline $\mathbf{B}_{18}$ & LIG 1H1-ASP 73 O & 1.840 & LIG 1H-PHE 196 O & 2.417 & LIG 1 H-HSE 45 O & 1.991 \\
\hline
\end{tabular}

\section{Molecular docking studies of designed compounds with} DNA gyrase subunit B (PDB ID: 1KZN): DNA gyrase is a type II topoisomerase, present in all bacteria and plays a vital role in the regulation of topological state of DNA. Relaxation of supercoiled DNA is important requirement for the bacterial transcription, replication and inhibition of DNA gyrase blocks this relaxation step. DNA gyrase is a specific, selective and interesting target for antibacterial agents such as widely studied coumarin antibiotics, e.g. clorobiocin [29].

Molecular docking results showed that except few $\left(B_{1}\right.$, $\mathrm{B}_{2}$ and $\mathrm{B}_{4}$ ), all the designed compounds displayed moderate to good binding affinity towards DNA gyrase (Table-3). It can be suggested that substituted phenyl ring is more interactive with the enzyme than the unsubstituted phenyl ring $\left(\mathrm{B}_{1} ; \Delta \mathrm{G}=\right.$ $-7.55 \mathrm{kcal} / \mathrm{mol}$ ), as the phenyl substituted derivatives showed improved affinity towards the active site. It was interesting to observe that when the phenyl ring is substituted with electron withdrawing groups, binding affinity was significantly improved. In case of 4-chloro-3-nitro derivative $\left(\mathrm{B}_{13}\right)$ and 3,5-dinitro derivative $\left(\mathrm{B}_{17}\right), \Delta \mathrm{G}$ scores were -8.32 and $-8.30 \mathrm{kcal} / \mathrm{mol}$, respectively, suggesting that they can interact well with the active site.

Binding modes of the title compounds were compared with the binding mode of coumarin class of drug, clorobiocin. Clorobiocin formed hydrogen bonding interactions with critical amino acids such as ASP 73, ASN 46, GLY 77 and ARG 136. All the compounds displayed effective binding affinity towards the target enzyme and interactions were noted with GLU 42, GLU 58, ASN 46, ASP 49, ASP 73, GLN 72and GLY 117. These observations indicated that designed compounds acquired similar binding pose as that of clorobiocin.
Among all the derivatives, stearyl derivative $\left(\mathrm{B}_{6}\right)$ exhibited the maximum binding affinity $(-9.09 \mathrm{kcal} / \mathrm{mol})$, followed by the oleayl derivative $B_{7}$ with good binding affinity $-9.04 \mathrm{kcal} /$ mol, which can be compared with the binding affinity of standard inhibitor, clorobiocin $(\Delta \mathrm{G}=-10.08 \mathrm{kcal} / \mathrm{mol}$ ) (Table3 ). Binding modes of stearyl, oleayl substituted derivatives and the standard drug clorobiocin are shown in Figs. 1 and 2, respectively.

Highly interactive stearyl derivative $\left(\mathrm{B}_{6}\right)$ formed hydrogen bonds with GLU 42 and ASN 46. In the preferred binding pose, hydrogens attached to the free amino group substituted at $4^{\text {th }}$ position of 1,2,4-triazole ring formed hydrogen bonds with oxygen of GLU 42 and ASN 46 with bond lengths of $2.151 \AA$ and $2.541 \AA$, respectively and hydrogens attached to the free thiol group substituted at 3 rd position of 1,2,4-triazole ring formed hydrogen bonds with oxygen of GLU 42 with bond lengths of 2.796 and $1.968 \AA$. Similarly for the oleayl derivative $\mathrm{B}_{7}$ hydrogen bonds were found with GLU 58, GLN 72 and ASP 73. In this case, hydrogens attached to the free amino group substituted at $4^{\text {th }}$ position of 1,2,4-triazole ring formed hydrogen bonds with oxygen of GLN 72 and ASP 73 with bond lengths of $2.403 \AA$ and $2.261 \AA$, respectively and hydrogens attached to the free thiol group substituted at 3 rd position of 1,2,4-triazole ring formed hydrogen bonds with oxygen of GLU 58 with bond length of $2.742 \AA$.

Lipophilic and unsaturated fatty acid substitution on 1,2,4triazole scaffold has resulted in the potent compounds which can effectively bind with the DNA gyrase enzyme. With these results, it can be predicted that the active site of enzyme can accommodate bulky and lipophilic moieties. 


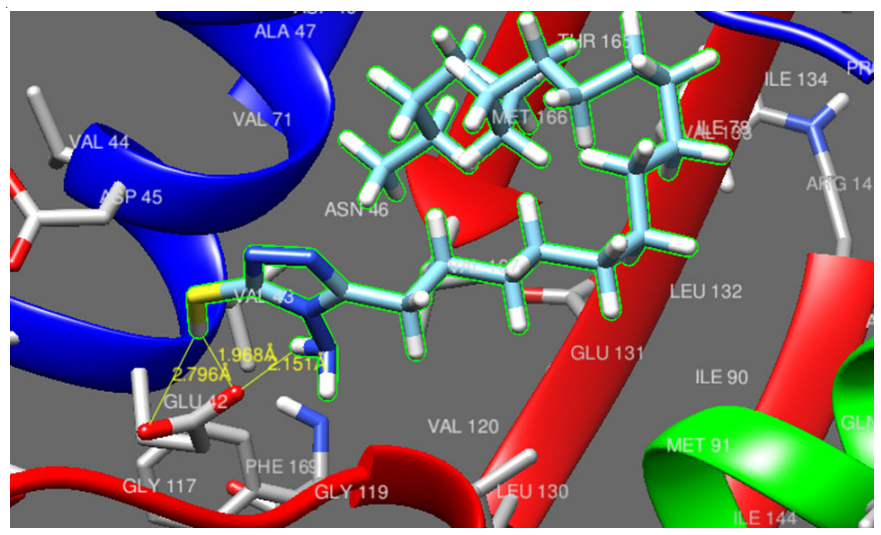

(a)

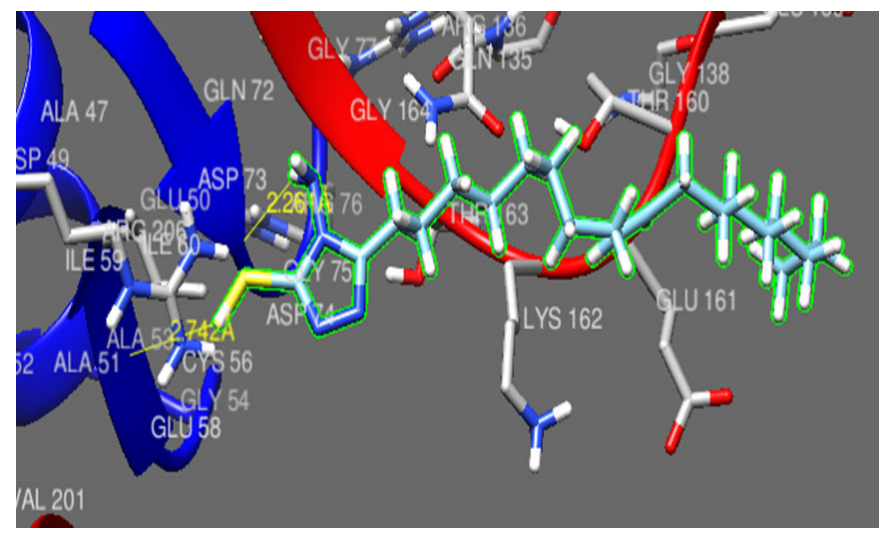

(b)

Fig. 1. Binding interactions of $\mathrm{B}_{6}$ and $\mathrm{B}_{7}$ with DNA gyrase subunit $\mathrm{B}$ (presentation in ribbon style)

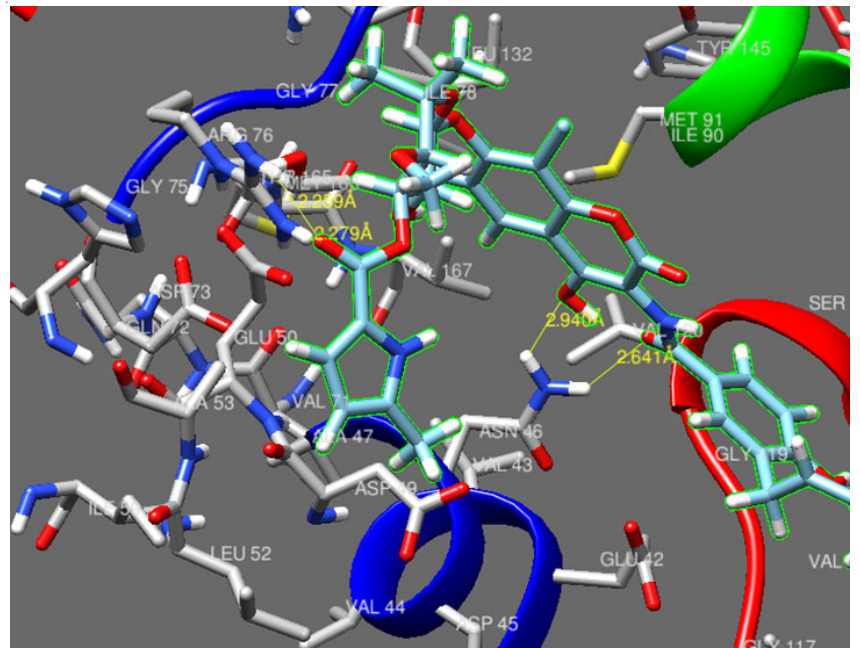

Fig. 2. Interactive ribbon representation of clorobiocin with DNA gyrase subunit B

Molecular docking studies of designed compounds with COX-2 (PBD ID: 3LN1): Cyclooxygenases (COXs) or prostaglandin endoperoxide synthases are important enzymes for the synthesis of prostaglandins which are the key mediators of pain, inflammation and hyperpyrexia. Out of two isoforms of COX enzymes, COX-2 is the specific one and it selectively involved in pain and inflammation and plays a grand role in prostaglandin biosynthesis in inflammatory cells and CNS. COX-2 inhibition has two advantages over COX-1 inhibition: very less gastric irritation and reduced risk of peptic ulceration. Celecoxib is the most effective COX-2 inhibitor [30].

Most of the designed compounds displayed moderate to good binding affinity towards the target enzyme. The highest binding affinity was observed with stearyl and oleayl derivatives $\left(\mathrm{B}_{6}\right.$ and $\left.\mathrm{B}_{7}\right)$ with binding scores of -8.83 and $-8.88 \mathrm{kcal} /$ $\mathrm{mol}$, respectively comparable to celecoxib $(-10.17 \mathrm{kcal} / \mathrm{mol})$, a good anti-inflammatory agent. $\mathrm{B}_{6}$ and $\mathrm{B}_{7}$ also showed good interactions with DNA gyrase enzyme. The influence of substitution on phenyl ring on binding interactions and $\Delta \mathrm{G}$ was found similar even with COX-2 enzyme; all substituted phenyl derivatives showed improved affinity towards the target active site when compared to the unsubstituted phenyl $\operatorname{ring}\left(\mathrm{B}_{1} ; \Delta \mathrm{G}=-7.55 \mathrm{kcal} /\right.$ $\mathrm{mol})$. It was noted that 2-hydroxy-3,5-dinitro derivative $\left(\mathrm{B}_{8}\right)$ displayed better affinity with $\Delta \mathrm{G}$ of $-8.75 \mathrm{kcal} / \mathrm{mol}$ and all other derivatives showed $\Delta \mathrm{G}$ in the range -7.45 to $-8.75 \mathrm{kcal} / \mathrm{mol}$.

Binding modes of highly interactive stearyl, oleayl substituted derivatives $\left(\mathrm{B}_{6}\right.$ and $\left.\mathrm{B}_{7}\right)$ and celecoxib are shown in Figs. 3 and 4 , respectively. The designed compounds were found to interact with the active site through hydrogen bonds with ASN 19, ARG 139, THR 198, GLU 222, GLU 275, GLU 276, ASP

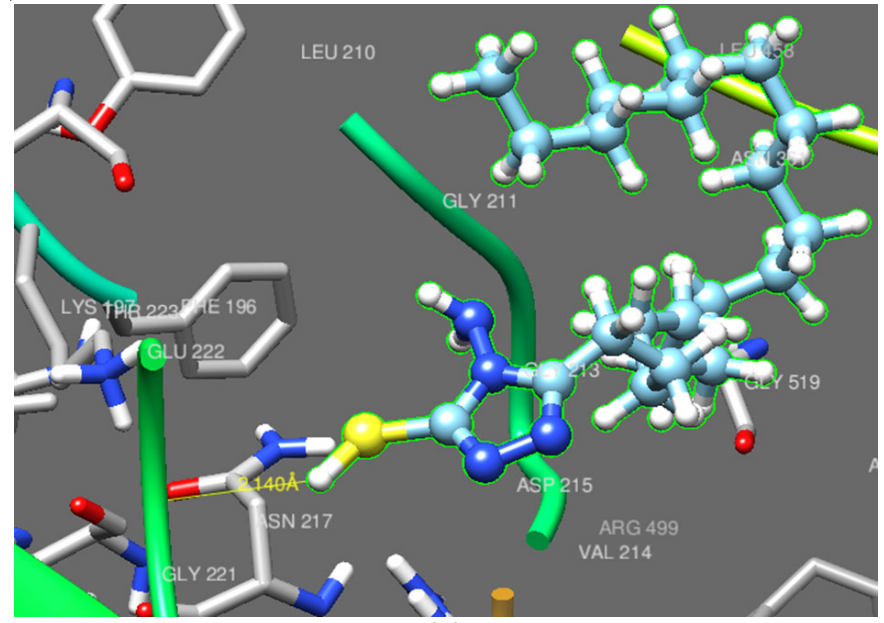

(a)

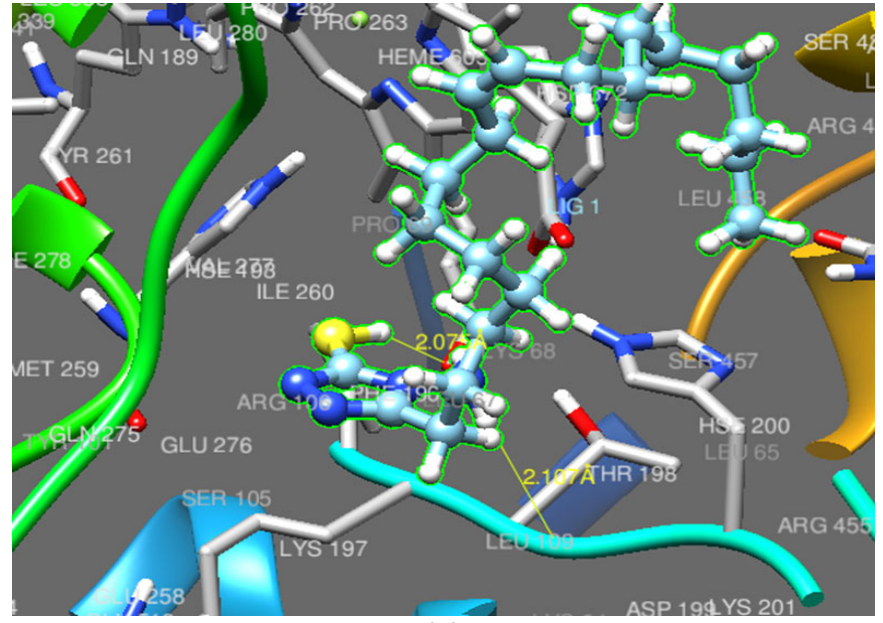

(b)

Fig. 3. Binding interactions of $\mathrm{B}_{6}$ and $\mathrm{B}_{7}$ with $\mathrm{COX}-2$ representation in ribbon mode 


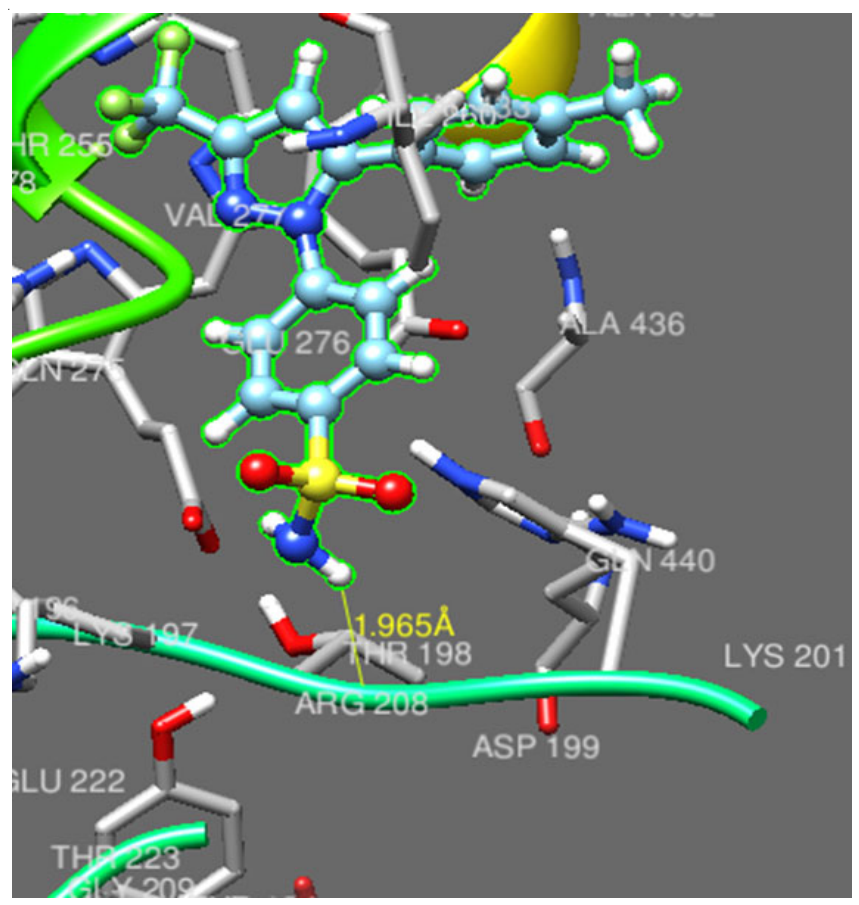

Fig. 4. Interactive ribbon representation of celecoxib with COX-2 interacting with THR 198, ASP 215

333, GLN 440, PHE 566 and HEME 605. Oleayl derivative $\left(\mathrm{B}_{7}\right)$ interacted with GLN 440 and HEME 605 and it was observed hydrogens attached to the free amino group substituted at $4^{\text {th }}$ position of 1,2,4-triazole ring formed hydrogen bonds with oxygen of THR 198, hydrogens attached to the free thiol group substituted at $3^{\text {rd }}$ position of 1,2,4-triazole ring formed hydrogen bonds with oxygen of HEME 605 and nitrogen at $2^{\text {nd }}$ position of 1,2,4-triazole ring formed hydrogen bonds with hydrogen of GLN 275 with bond lengths of 2.107, 2.075 and $2.360 \AA$, respectively. Similarly the stearyl derivative $\left(\mathrm{B}_{6}\right)$ also participated in hydrogen bond by the hydrogens attached to the free amino group substituted at $4^{\text {th }}$ position of 1,2,4-triazole ring and formed hydrogen bonds with oxygen of ASP 215 . The hydrogens attached to the free thiol group substituted at 3rd position of 1,2,4-triazole ring formed hydrogen bonds with oxygen of GLY 221 within the distance $1.921 \AA$ and $2.140 \AA$, respectively.
Binding modes of stearyl, oleayl substituted derivatives and celecoxib as shown in Figs. 5 and 6, respectively.

Molecular docking studies of designed ligands with cathepsin B (PBD ID: 1SP4): Cathepsin, a cysteine protease enzyme that belongs to papain super family. It is highly implicated in tumerigenesis and also acts as prognostic marker for several cancer types. Cysteine cathepsins have crucial role in metastasis, as bone is the most common site of distant metastasis in breast cancer patients, identifying cysteine cathepsins role in bone metastasis is a difficult task. Thus it was suggested that cathepsin B is an efficient therapeutic target for the management of breast cancer patients with metastatic disease. Selective cathepsin B inhibition is a significant way to reduce metastasis and also produces therapeutic potential [31]. Design of cathepsin B inhibitors is a challenging and difficult task, because of central and crucial role played by it in tumour progression and invasion [32].

Molecular docking studies were performed by retrieving the crystal structures of ligand and NS134 from Protein Data Bank (RCSB) (http://www.rcsb.org/pdb). Molecular docking studies showed that among all 18 designed compounds, higher binding affinity was observed with stearyl and oleayl derivatives $\left(B_{6}\right.$ and $\left.B_{7}\right)$ with the scores -9.11 and $-9.39 \mathrm{kcal} / \mathrm{mol}$, respectively and that is comparable to NS-134 (-10.35 kcal $/ \mathrm{mol})$, a good anticancer agent (Table-3). Remaining compounds were moderately interactive with the binding scores in the range -7.23 to $-8.10 \mathrm{kcal} / \mathrm{mol}$. The designed compounds were found to form hydrogen bond interactions with GLU 122, HSE 110, HSD 111, CYS 119, HSD 145 and TRP 221 in the active site. The following interactions were observed for stearyl and oleayl derivative $\left(\mathrm{B}_{6}\right.$ and $\left.\mathrm{B}_{7}\right)$ :

i) Hydrogens attached to the free amino group substituted at $4^{\text {th }}$ position of 1,2,4-triazole ring formed hydrogen bonds with oxygen of GLU 122 (bond length: 2.155 and $2.336 \AA$ ).

ii) Hydrogens attached to the free thiol group substituted at 3rd position of 1,2,4-triazole ring formed hydrogen bonds with nitrogen of HSE 110 (bond length: 2.132 and $2.546 \AA$ ).

iii) Nitrogen at $2^{\text {nd }}$ position of 1,2,4-triazole ring formed hydrogen bonds with hydrogen of TRP 221 (bond length: 2.293 and $2.378 \AA$ ) (Figs. 5 and 6).

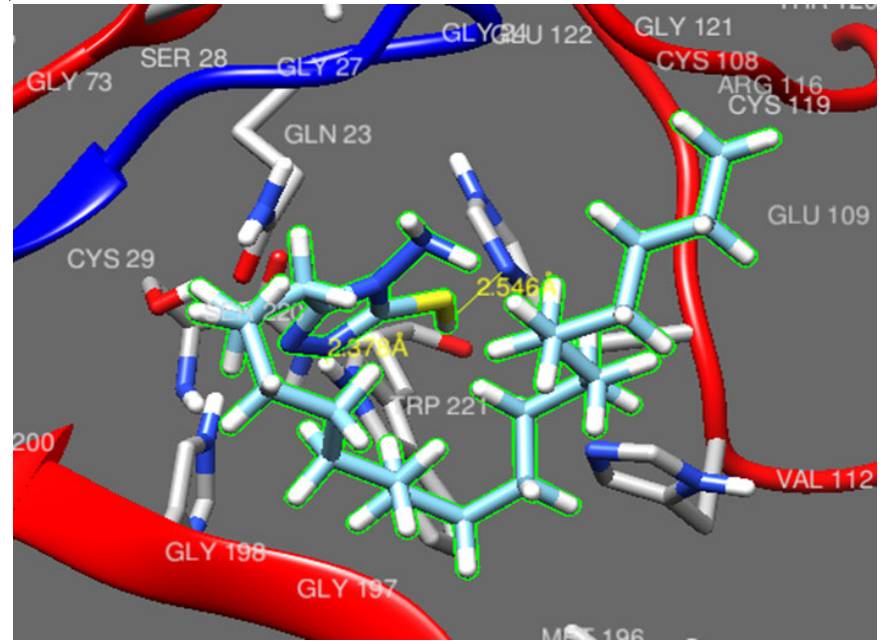

(a)

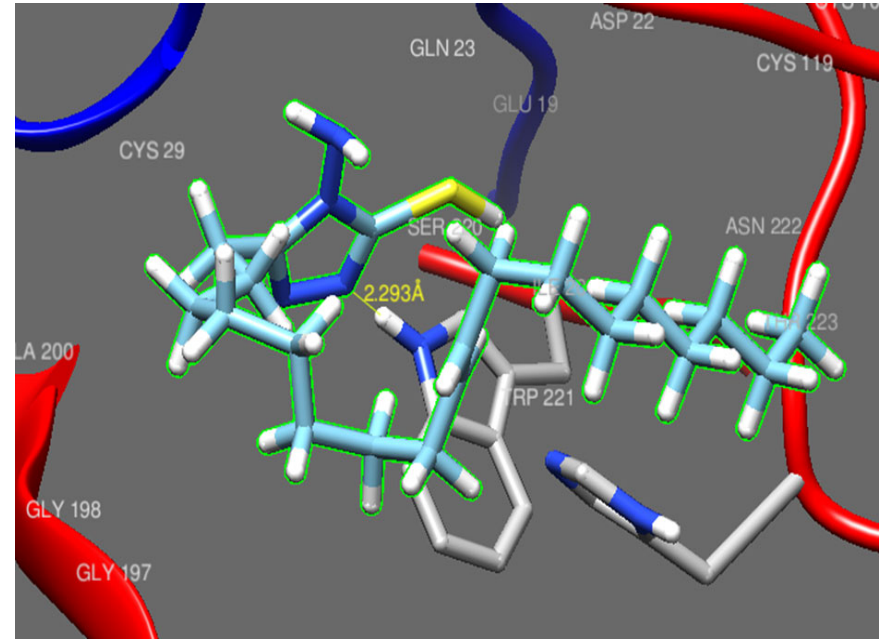

(b)

Fig. 5. Binding interactions of $\mathrm{B}_{6}$ and $\mathrm{B}_{7}$ with cathepsin $\mathrm{B}$ representation in ribbon mode 


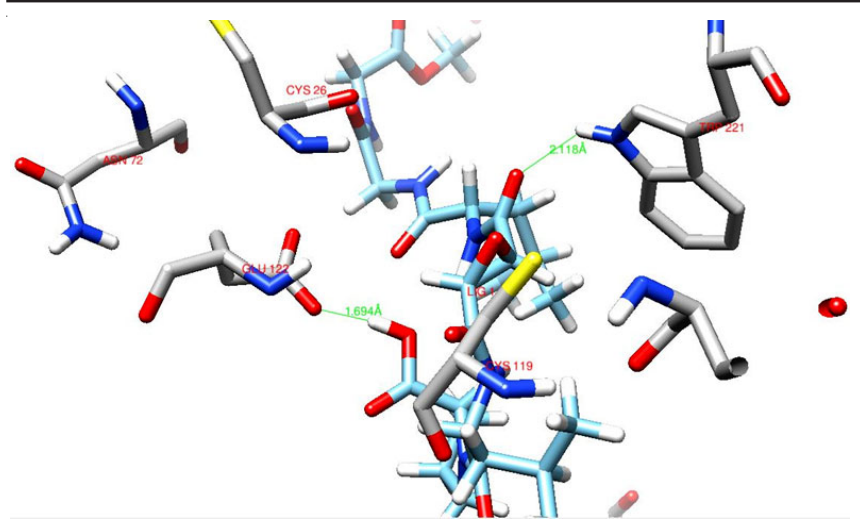

Fig. 6. Interactive representation of NS 134 with cathepsin B (PDB ID: 1SP4) with TRP 221 and GLU 122

In summary, designed compounds showed relatively good affinity for cathepsin B and DNA gyrase enzymes when compared to COX-2. The compounds were able to attain binding poses so as to interact with key residues of the selected targets. The most significant interactions that contributed to proteinligand binding free energy include participation of free thiol and amino groups positioned at $3^{\text {rd }}$ and $4^{\text {th }}$ positions of $1,2,4-$ triazole ring. Substitution at $5^{\text {th }}$ position significantly improved the affinity of the compounds for the active sites. Presence of phenyl ring substituted with electron withdrawing groups seems to be more favourable in this aspect. Styryl and pyridyl rings also enhanced the binding abilities of the molecules. Moreover, compounds $\mathrm{B}_{6}$ and $\mathrm{B}_{7}$ exhibited higher selectivity (comparable to the standard drugs) towards all the target enzymes as the non polar chains were well accommodated in the binding pockets. On the basis of the results produced from the in silico studies and docking, active compounds will be synthesized and evaluated for their therapeutic efficacy in the treatment of bacterial infections, inflammation and cancer.

\section{Conclusion}

Good binding affinities were observed by the title compounds towards the targets (DNA gyrase sub unit B, COX-2 and cathepsin B). The key scaffold, 4-amino-4H-1,2,4-triazole3-thiol ring formed several hydrogen bonds with crucial amino acids of the selected targets. Interesting results were obtained when $5^{\text {th }}$ position is substituted and it is evident that stearyl and oleayl group substitution $\left(\mathrm{B}_{6}\right.$ and $\left.\mathrm{B}_{7}\right)$ is promising. This study also implies that the designed compounds have favourable pharmacokinetic properties and their cellular uptake is not affected by $\mathrm{P}$-glycoprotein.

\section{CONFLICT OF INTEREST}

The authors declare that there is no conflict of interests regarding the publication of this article.

\section{REFERENCES}

1. H.-Z. Zhang, G.L.V. Damu, G.-X. Cai and C.-H. Zhou, Curr. Org. Chem., 18, 359 (2014); https://doi.org/10.2174/13852728113179990025.

2. A.H. Malani, A.H. Makwana and H.R. Makwana, Moroccan J. Chem., 5, 41 (2017).

3. S.C. Holm and B.F. Straub, Org. Prep. Proc. Int., 43, 319 (2011); https://doi.org/10.1080/00304948.2011.593999.
4. S. Maddila, R. Pagadala and S.B. Jonnalagadda, Lett. Org. Chem., 10, 693 (2013);

https://doi.org/10.2174/157017861010131126115448.

5. B.T. Yin, C.Y. Yan, X.M. Peng, S.L. Zhang, S. Rasheed, R.X. Geng and C. Zhou, Eur. J. Med. Chem., 71, 148 (2014); https://doi.org/10.1016/j.ejmech.2013.11.003.

6. R. Kharb, P.C. Sharma and M.S. Yar, J. Enzyme Inhib. Med. Chem., 26, 1 (2011); https://doi.org/10.3109/14756360903524304.

7. H.A.M. El-Sherief, B.G.M. Youssif, S.N.A. Bukhari, A.H. Abdelazeem, M.A. Aziz and H.M.A. Rahman, Eur. J. Med. Chem., 156, 774 (2018); https://doi.org/10.1016/j.ejmech.2018.07.024.

8. N. Raghav and M. Singh, Eur. J. Med. Chem., 77, 231 (2014); https://doi.org/10.1016/j.ejmech.2014.03.007.

9. K.S. Bhat, B. Poojary, D.J. Prasad, P. Naik and B.S. Holla, Eur. J. Med. Chem., 44, 5066 (2009); https://doi.org/10.1016/j.ejmech.2009.09.010.

10. D.A. Al-Turki, M.A. Al-Omar, L.A. Abou-zeid, I.A. Shehata and M.S. Al-Awady, Saudi Pharm. J., 25, 59 (2017); https://doi.org/10.1016/j.jsps.2015.07.001.

11. L. Labanauskas, E. Udrenaite, P. Gaidelis and A. Brukstus, IL Farmaco, 59, 255 (2004); https://doi.org/10.1016/j.farmac.2003.11.002

12. S. Pattan, P. Gadhave, V. Tambe, S. Dengale, D. Thakur, S.V. Hiremath, R.V. Shete and P. Deotarse, Indian J. Chem., 51B, 297 (2012).

13. N. Muthal, J. Ahirwar, D. Ahriwar, P. Masih, T. Mahmdapure and T. Siva Kumar, Int. J. Pharm. Technol. Res., 2, 2450 (2010).

14. P. Valentina, K. Ilango, M. Deepthi, P. Harusha, G. Pavani, K.L. Sindhura and G. Keerthanan, J. Pharm. Sci. Res., 2, 74 (2009).

15. O. Demirkol, C. Adams and N. Ercal, J. Agric. Food Chem., 52, 8151 (2004); https://doi.org/10.1021/jf040266f.

16. C.A. Lipinski, F. Lombardo, B.W. Dominy and P.J. Feeney, Adv. Drug Deliv. Rev., 46, 3 (2001); https://doi.org/10.1016/S0169-409X(00)00129-0.

17. C.A. Lipinski, Drug Discov. Today. Technol., 1, 337 (2004); https://doi.org/10.1016/j.ddtec.2004.11.007.

18. P. Ertl, B. Rohde and P. Selzer, J. Med. Chem., 43, 3714 (2000); https://doi.org/10.1021/jm000942e.

19. U. Haberthur and A. Caflisch, J. Comput. Chem., 29, 701 (2008); https://doi.org/10.1002/jcc.20832.

20. A.K. Ghose, V.N. Viswanadhan and J.J. Wendoloski, J. Comb. Chem., 1, 55 (1999); https://doi.org/10.1021/cc9800071.

21. D.F. Veber, S.R. Johnson, H.-Y. Cheng, B.R. Smith, K.W. Ward and K.D. Kopple, J. Med. Chem., 45, 2615 (2002); https://doi.org/10.1021/jm020017n.

22. E.F. Pettersen, T.D. Goddard, C.C. Huang, G.S. Couch, D.M. Greenblatt, E.C. Meng and T.E. Ferrin, J. Comput. Chem., 13, 1605 (2004); https://doi.org/10.1002/jcc.20084.

23. D.G. Gfeller, A. Grosdidier, M. Wirth, A. Diana, M. Olivier and V. Zoete, Nucleic Acids Res., 42, W32 (2014); https://doi.org/10.1093/nar/gku293.

24. A. Grosdidier, V. Zoete and O. Michielin, Protein, 67, 1010 (2007); https://doi.org/10.1002/prot.21367.

25. A. Grosdidier, V. Zoete and O. Michielin, Nucleic Acids Res., 39(suppl), W270 (2011); https://doi.org/10.1093/nar/gkr366.

26. B. Arifa, B. Shaheen, K. Prasad and K. Bharathi, Int. J. Pharm. Pharm. Sci., 9, 209 (2017); https://doi.org/10.22159/ijpps.2017v9i8.19835.

27. D.S. Miller, Trends Pharmacol. Sci., 31, 246 (2010); https://doi.org/10.1016/j.tips.2010.03.003.

28. F. Li, X. Zhou, H. Zhou, J. Jia, L. Li, S. Zhai and B. Yan. B, PLoS One, 11, e0160042 (2016); https://doi.org/10.1371/journal.pone.0160042.

29. M.A. Ismail, S. Al-Shihry, R.K. Arafa and U. El-Ayaan, J. Enzyme Inhib. Med. Chem., 28, 530 (2013); https://doi.org/10.3109/14756366.2011.654113.

30. R. Jarapula, K. Gangarapu, S. Manda and S. Rekulapally, Int. J. Med. Chem., 2016, Article ID 2181027 (2016); https://doi.org/10.1155/2016/2181027.

31. N.P. Withania, G. Blum, M. Sameni, C. Slaney, A. Anbalagan and B. Mary Olive, Clin. Cancer Res., (2012).

32. J. Kos, A. Mitroviæ and B. Mirkoviæ, Future Med. Chem., 6, 1355 (2014); https://doi.org/10.4155/fmc.14.73. 